\title{
Direct to Consumer Advertising: The Case for Greater Consumer Control
}

\author{
Idris Guessous, MD, $P h D^{1,2,3}$ and Chiranjeev Dash, $M B B S, M P H, P h D^{4}$
}

'Unit of Population Epidemiology, Division of Primary Care Medicine, Department of Community Medicine, Primary Care, and Emergency Medicine, Geneva University Hospitals, Geneva, Switzerland; ${ }^{2}$ Division of Chronic Diseases, University Institute of Social and Preventive Medicine, Lausanne, Switzerland; ${ }^{3}$ Department of Epidemiology, Rollins School of Public Health, Emory University, Atlanta, GA, USA; ${ }^{4}$ Georgetown Lombardi Comprehensive Cancer Center, Georgetown University Medical Center, Washington, DC, USA.

KEY WORDS: direct-to-consumer advertising; benign prostatic hyperplasia; informed decision.

J Gen Intern Med 30(4):392-4

DOI: $10.1007 / \mathrm{s} 11606-015-3187-8$

(C) Society of General Internal Medicine 2015

A nyone traveling to the United States from countries other than New Zealand will be surprised by the prevalence of health-related advertisements on television, including ads for drugs. Typically, these TV ads follow a pattern: an ad for a burger at only 99 cents, followed by one for a proton-pump inhibitor, then an ad on healthy home-cooked food delivered directly to your home and an ad for a home-based abdominal workout DVD, followed by an ad for a lipid-lowering drug. There are, however, nuances. After $8 \mathrm{pm}$, the visitor might encounter an ad for the "little blue pill." This sequence sometimes includes an ad featuring antihistamines for allergic rhinitis in spring and one promoting antidepressants in the winter.

Such direct-to-consumer advertising (DTCA) of prescription drugs is usual business in the United States and New Zealand but is prohibited in the rest of the world. Why? Because DTCA for prescribing drugs has pros and cons (discussed elsewhere, ${ }^{1-3}$ including in $\mathrm{JGIM}^{4}$ ) that are balanced differently in different countries. Constitutional factors - such as the First Amendment protections on speech, including commercial speech, in the United States ${ }^{5}$-as well as patient and population safety considerations, which all differ across countries, modulate reactions to DTCA. Additionally, lack of robust data on the impact of DTCA on prescription drug use adds to the confusion. Evidence, though limited, suggests that DTCA increases drug sales. However, whether the increase in sales corrects existing underuse or encourages over/misuse is not clear. ${ }^{6}$

A related issue is whether DTCA can potentially shift prescribing from recommended to suboptimal therapy. In this issue of JGIM, Skeldon et al. ${ }^{7}$ have addressed the impact of sequential DTCA campaigns for two treatments for lower urinary tract symptoms (LUTS) associated with benign prostatic hyperplasia $(\mathrm{BPH})$ : one older agent (tamsulosin; Flomax $^{\circledR}$ ) and one newer agent (dutasteride; Avodart ${ }^{\circledR}$ ).

Published online January 22, 2015
Tamsulosin is an alpha-blocker that relaxes the prostatic smooth muscle to relieve bladder outlet obstruction. Dutasteride is a 5-alpha reductase inhibitors (5-ARI) that reduces the size of the prostate. Skeldon et al. state that because of its "efficacy, rapid effect, and lower sexual side effects," tamsulosin is the "first-line" drug for $\mathrm{BPH}^{7}$ The authors used data from Google Trends and IMS Health (a provider of pharmaceutical market intelligence) and conducted an interrupted time-series analysis. From Google Trends, the authors collected the volume of searches for "Avodart" and "Flomax" between 2004 and 2007. From IMS Health, the authors collected data on the monthly prescription rates for tamsulosin and dutasteride from 2003 to 2007. They compared these data in parallel to DTCA campaigns for dutasteride and tamsulosin that started, respectively, in July 2005 and April 2006 in the United States. This study is the first to explore the effect of DTCA campaigns for two different classes of drugs from two different firms for roughly the same therapeutic indication. Although the authors used the specific case of LUTS/BPH, which is a common condition encountered in primary care, ${ }^{8}$ the results are, at least in part, generalizable to other frequent chronic and undertreated health conditions. The authors found that: 1) each DTCA drug campaign actually increased the volume of Internet searches for both "first-line" and "second-line" drugs; and 2) each DTCA campaign also increased sales for both drugs, but more so for the "first-line" drug, irrespective of which drug was advertised. The authors concluded that because DTCA campaigns appeared to increase "first-line" treatments to a greater extent than "second-line" treatments, DTCA may be effective for achieving compliance to medical guidelines and recommendations. Overall, this study highlights an important potential benefit of DTCA. Like others, Skledon et al. stressed the role of physicians as gatekeepers of DTCA, given that these drugs need to be prescribed. The authors postulated that after a careful history and physical examination, physicians' decisions will be guided by the clinical context. This is, at least in part, in line with results from the single robust evidence of DTCA on physicians' prescriptions in a community-based randomized trial of the influence of patient requests for DTCA drugs on antidepressant prescription. ${ }^{9}$ Of note, administrative and/or organizational constraints can also influence the decision. 
There are, however, caveats to these interpretations. While the authors explicitly mention as limitations of their study the lack of direct information on the intensity and length of both DTCA campaigns and the use of Google Trends only to assess search volume, our main concern relates to the choice of tamsulosin and dutasteride for testing the effect of competing DTCA campaigns on prescription patterns of "first-line" and "second-line" drugs. The two classes of drugs investigated are not really "first-line" (alpha-blockers) or "second-line" (5ARI), because rather than being based on "efficacy, rapid effect, and lower sexual side effects," the choice of monotherapy between the two drug classes or a combination therapy for LUTS/BPH medical management is based on the presence or absence of prostate enlargement as measured by prostate volume, PSA levels, and/or a digital rectal exam (DRE). The 2003 (and the 2010) AUA BPH guidelines ${ }^{10}$ stated that "alfuzosin, doxazosin, tamsulosin and terazosin are appropriate treatment options for patients with lower urinary tract symptoms secondary to BPH," and that "the 5-ARI finasteride and dutasteride are appropriate and effective treatments for patients with lower urinary tract symptoms associated with demonstrable prostatic enlargement." In fact, the combination of an alpha-blocker and a 5-ARI is also an appropriate and effective treatment for patients with LUTS associated with demonstrable prostatic enlargement. ${ }^{10}$ Tamsulosin and dutasteride have different complementary indications and are not direct competitors. Was the additional impact of the dutasteride DTCA campaign on tamsulosin prescriptions appropriately mediated by patients without prostatic enlargement? Was the additional impact of the tamsulosin DTCA campaign on dutasteride prescriptions appropriately mediated by patients with prostatic enlargement? Moreover, did DTCA campaigns shift the therapy of BPH patients with moderate to severe symptoms not bothered by LUTS from watchful waiting to drug management (which might arguably be less appropriate)? And finally, what was the effect of these DTCA campaigns on prescription patterns of older alpha-blockers (doxazosin and terazosin) that are less expensive, require once-daily dosing, and remain excellent treatment choices for LUTS/BPH compared to the more expensive tamsulosin, which requires twice-daily dosing? ${ }^{10}$ These are important questions that cannot be answered with the data at hand, and studies are needed to determine whether prescriptions of drugs advertised by DTCA are guided by clinical indications, are appropriate, and convey benefits commensurate with their costs.

There is another issue to consider. It has been implicitly assumed by Skeldon et. al. that prescription patterns were driven by consumer-directed advertising. Although DTCA for prescription drugs is a $\$ 5$ billion per year industry in the United States, it pales in comparison to the $\$ 20$ billion spent annually by the pharmaceutical industry to advertise directly to health care professionals. The impact of physician-directed advertising on prescription patterns of these drugs is likely greater than DTCA, and should be adjusted for in future studies of DTCA's impact on prescribing.

Meanwhile, we share the view that DTCA of prescription drugs should not be abandoned, but rather controlled. ${ }^{11}$ We are, however, skeptical that the formation of an independent agency funded, in part, by the pharmaceutical industry that would produce unbiased consumer materials is the best way to control DTCA. ${ }^{4,12}$ After all, the United States Food and Drug Administration (FDA), which has a dedicated office to review DTCA (Office of Prescription Drug Promotion), has faced considerable challenges in reviewing and controlling DTCA content. ${ }^{13}$ More creative and innovative methods are needed to ensure that consumers and patients get targeted, factually correct, and complete information on drug indications, uses, and side-effects through DTCA. Consumer education on DTCA content, including the benefits and drawbacks of DTCA, is one method to increase consumer awareness regarding DTCA. Most DTCA are superficial in their coverage of medical conditions and their treatments, and propositions have been made to improve the very low educational value of current DTCA. ${ }^{14}$ DTC information ads could explain to consumers the purpose, structure and content of DTCA. Ideally, they should be produced and ideally aired on the same channels and programs that frequently air DTCA. The FDA, the pharmaceutical industry, and the lay media industry should be equally responsible for the cost of airing these DTC information ads. Another alternative is a Patient/Consumer television control device, whereby consumers could make an individualized informed decision on watching TV with or without DTCA (this would include consumer education on DTCA). This approach has several advantages: 1) it respects the First Amendment, 2) it respects individual choice, 3) it limits the resources needed to provide balanced and fair information because information on the risk and benefits of DTCA in general could be provided before opting in or out of DTCA, and 4) is reversible, as patient control can be modified. There are some barriers to this approach, including use of legislation to make sure pharmaceutical and media companies participate, a fair determination of who pays for these consumer education messages and technology associated with individual controls, development of technology that allows consumers to skip all ads, provision of culturally relevant and health literacy-relevant information, and increased consumer reliance on active, web-based information seeking than on passive, TV-based methods. However, it is now common sense and usual practice to profile TV and internet content based on individual viewers' choice. Adults can choose to view content containing sexually explicit or violent material that they judge appropriate and/or useful for them, while deciding to forgo content they judge inappropriate or not useful. Why couldn't this be so for health content as well?

Conflict of Interest: The authors declare that they do not have a conflict of interest. 
Corresponding Author: Idris Guessous, MD, PhD; Unit of Population Epidemiology, Division of Primary Care Medicine, Department of Community Medicine, Primary Care, and Emergency MedicineGeneva University Hospitals, Geneva, Switzerland (e-mail: idris.guessous@hcuge.ch).

\section{REFERENCES}

1. Holmer AF. Direct-to-consumer prescription drug advertising builds bridges between patients and physicians. JAMA. 1999;281(4):380-2.

2. Mintzes B. Advertising of prescription-only medicines to the public: does evidence of benefit counterbalance harm? Annu Rev Public Health. 2012;33:259-77.

3. Stange KC. Time to ban direct-to-consumer prescription drug marketing. Ann Fam Med. 2007;5(2):101-4.

4. Ross JS, Kravitz RL. Direct-to-consumer television advertising: time to turn off the tube? J Gen Intern Med. 2013;28(7):862-4.

5. Shuchman M. Drug risks and free speech—can Congress ban consumer drug ads? N Engl J Med. 2007;356(22):2236-9.

6. Fain KM, Alexander GC. Mind the gap: understanding the effects of pharmaceutical direct-to-consumer advertising. Med Care. 2014;52(4):291-3.

7. Skeldon SC, Kozhimannil KB, Majumdar SR, Law MR. The effect of competing direct-to-consumer advertising campaigns on the use of drugs for benign prostatic hyperplasia: time series analysis. J Gen Intern Med. 2014. doi:10.1007/s11606-014-3063-y.

8. Collins MM, Barry MJ, Bin L, Roberts RG, Oesterling JE, Fowler FJ. Diagnosis and treatment of benign prostatic hyperplasia. Practice patterns of primary care physicians. J Gen Intern Med. 1997;12 (4):224-9.

9. Kravitz RL, Epstein RM, Feldman MD, Franz CE, Azari R, Wilkes MS, Hinton L, Franks P. Influence of patients' requests for direct-to-consumer advertised antidepressants: a randomized controlled trial. JAMA. 2005;293(16):1995-2002.

10. AUA Practice Guidelines Committee. AUA guideline on management of benign prostatic hyperplasia (2003). Chapter 1 : diagnosis and treatment recommendations. J Urol. 2003;170(2 Pt 1):530-47.

11. Kravitz RL, Bell RA. Direct-to-consumer advertising of prescription drugs: balancing benefits and risks, and a way forward. Clin Pharmacol Ther. 2007;82(4):360-2.

12. Kravitz RL, Bell RA. Media, messages, and medication: strategies to reconcile what patients hear, what they want, and what they need from medications. BMC Med Informa Decis Making. 2013;13(Suppl 3):S5.

13. Donohue JM, Cevasco M, Rosenthal MB. A decade of direct-toconsumer advertising of prescription drugs. N Engl J Med. 2007;357(7):673-81.

14. Bell RA, Wilkes MS, Kravitz RL. The educational value of consumertargeted prescription drug print advertising. J Fam Pract. 2000;49 (12): 1092-8. 